Fetal Diagnosis and Therapy

\title{
Chromosomal Microarray Analysis in Fetuses with Growth Restriction and Normal Karyotype: A Systematic Review and Meta-Analysis
}

\author{
Antoni Borrell ${ }^{a} \quad$ Maribel Grande ${ }^{a} \quad$ Montse Pauta ${ }^{a} \quad$ Laia Rodriguez-Revengab \\ Francesc Figueras $^{\mathrm{a}}$ \\ ${ }^{a}$ BCNatal, Department of Maternal-Fetal Medicine, Institute of Gynecology, Obstetrics, and Neonatology, \\ Hospital Clínic Barcelona, and ${ }^{b}$ Centre de Diagnòstic Biomèdic, Hospital Clínic Barcelona, Barcelona, Catalonia, \\ Spain
}

\section{Keywords}

Prenatal diagnosis · Fetal growth restriction - Chromosomal microarray analysis · Copy number variants · Incremental yield

\begin{abstract}
Objective: To perform a systematic review of the literature and a meta-analysis to estimate the incremental yield of chromosomal microarray analysis (CMA) over karyotyping in fetal growth restriction (FGR). Methods: This was a systematic review conducted in accordance with the PRISMA criteria. All articles identified in PubMed, Ovid Medline, and ISI Web of Knowledge (Web of Science) from January 2009 to November 2016 describing pathogenic copy number variants (CNVs) in fetuses with growth restriction were included. Case reports were excluded. Risk differences were pooled to estimate the overall and stratified CMA incremental yield. Results: Ten studies with full data available met the inclusion criteria for analysis. Combined data from these studies revealed a $4 \%$ (95\% confidence interval $[\mathrm{Cl}] 1-6 \%$ ) incremental yield of CMA over karyotyping in nonmalformed growth-restricted fetuses, and a 10\% (95\% Cl6-14\%) incremental yield in FGR when associated with fetal malformations. The most frequently found pathogenic CNVs were 22q11.2 duplica-
\end{abstract}

tion, Xp22.3 deletion, and 7q11.23 deletion (Williams-Beuren syndrome), particularly in isolated FGR. Conclusion: The use of genomic CMA provides a $4 \%$ incremental yield of detecting pathogenic CNVs in fetuses with isolated growth restriction and normal karyotype.

(c) 2017 S. Karger AG, Basel

\section{Introduction}

Chromosomal anomalies have been reported to account for up to $19 \%$ of fetuses with fetal growth restriction (FGR), with triploidy and trisomy 18 being the most common anomalies in fetuses before and after 26 weeks of gestation, respectively [1]. However, the incidence of submicroscopic duplications/deletions and single-gene disorders in FGR and normal karyotype is not well established. A classic dysmorphology textbook showed that more than half of the reported microdeletion syndromes have postnatal growth restriction as a feature, although it must be taken into account that in some cases it may be produced by postnatal factors that did not exist prenatally, such as feeding difficulties, developmental delay with low muscle tone, or cardiac or renal dysfunctions [2].

\section{KARGER}

(c) 2017 S. Karger AG, Basel

E-Mail karger@karger.com

www.karger.com/fdt
Dr. Antoni Borrell, MD, PhD

BCNatal, Department of Maternal-Fetal Medicine

Institute of Gynecology, Obstetrics, and Neonatology, Hospital Clínic Barcelona

Sabino de Arana 1, ES-08028 Barcelona, Catalonia (Spain)

E-Mail aborrell@ clinic.cat 
Chromosomal microarray analysis (CMA) is a molecular technique that detects copy number variants (CNVs), submicroscopic gains or losses of DNA with a variable resolution down to $10 \mathrm{~Kb}$ or more within the genome, undetectable by conventional karyotyping. Although it is well established that a 6-11\% incremental yield of CMA as compared with conventional karyotyping is observed in fetuses with structural anomalies [3-7], a specific FGR subgroup is rarely considered. Hence, few studies have reported detection rates for FGR fetuses, ranging from 2 to $17 \%$ in isolated FGR, and from 4 to $21 \%$ in FGR in association with structural anomalies [3, 8-14]. In addition, no specific recommendation for fetuses with FGR is included in any of the CMA guidelines issues by scientific societies [15-18].

In this systematic review, we aimed to assist clinicians in antenatal counseling by estimating the incremental yield of pathogenic CNVs using CMA in pregnancies with FGR, particularly isolated FGR, and normal karyotype.

\section{Methods}

Eligibility Criteria, Information Sources, and Search Strategy

A systematic search was conducted focusing on studies written in English performing genomic analysis on fetuses diagnosed with FGR at ultrasound examination, according to the PRISMA guidelines. Electronic searches of the PubMed, Ovid Medline, and ISI Web of Knowledge (Web of Science) databases were performed using the search terms "fetal growth restriction" or "prenatal growth restriction," or "intrauterine growth restriction" or "ultrasound anomaly," and "array comparative genomic hybridization" or "copy number variation," with related search terms, from January 2009 to November 2016 (the complete search string is available in online suppl. Table 1S; for all online suppl. material, see www. karger.com/doi/10.1159/000479506).

This study is a review of previously published data and, such as, does not require ethics approval. The data were not used for any purpose other than those of the original study, and no new data were collected.

\section{Study Selection and Data Extraction}

Studies were selected in a two-step process. Initially, all titles and abstracts were reviewed by two researches (A.B. and M.G.), and potentially eligible full articles were extracted. Only original research articles using CMA on prenatal samples with abnormal ultrasound findings were reviewed in full text, including isolated FGR. Studies including fetuses with FGR and normal karyotype were identified and included in the analysis. When karyotyping was not performed prior to CMA (because it was performed simultaneously or not at all), cases with a genomic imbalance $>10 \mathrm{Mb}$ were considered detectable by karyotyping and therefore excluded from our analysis. Data on selection criteria, CMA resolution, fetal ultrasound findings (whether the FGR was isolated or associated

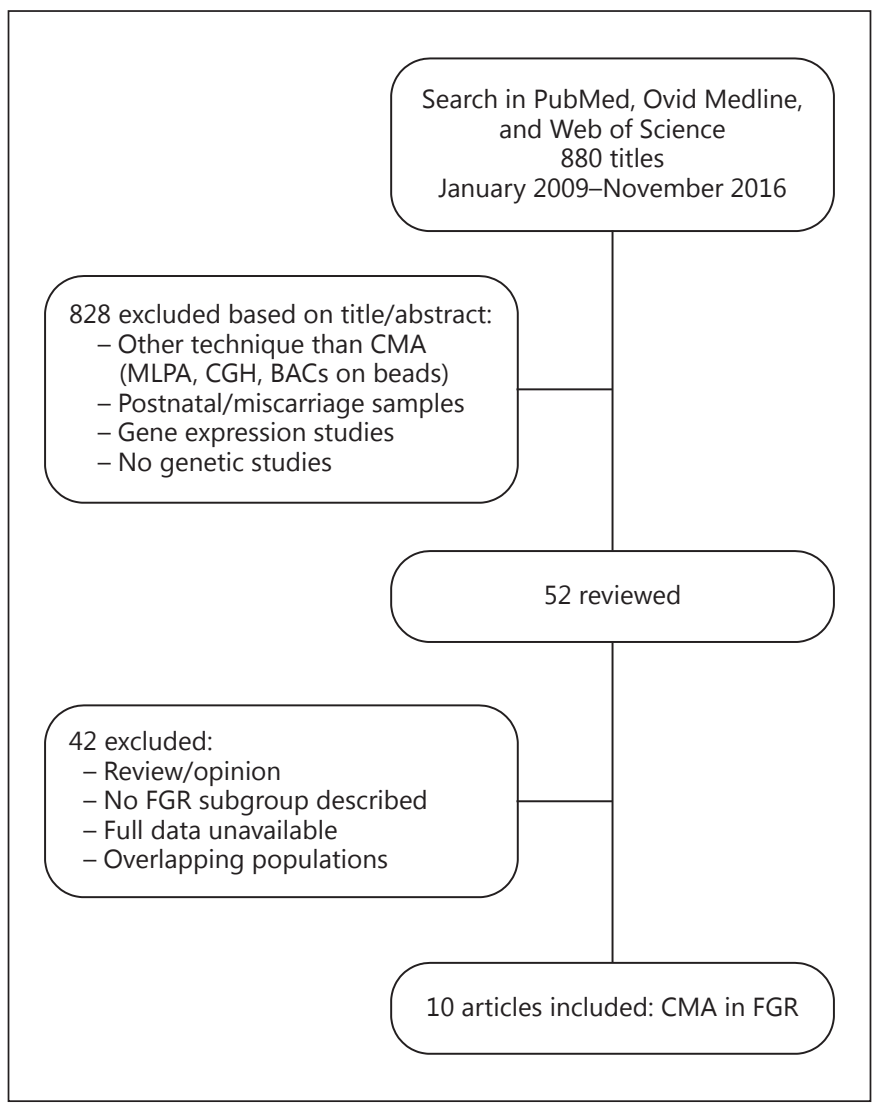

Fig. 1. Study revision and selection algorithm. FGR, fetal growth restriction.

with other fetal anomalies), and CNV description were extracted from these studies. Authors of series including fetuses with abnormal ultrasound findings in which an FGR subgroup was not analyzed were contacted and asked to provide further details. Reported CNVs were reviewed by two authors independently (M.G. and L.R.R.) to evaluate clinical significance. Any disagreement was resolved by discussion.

\section{Assessment of Risk of Bias}

Quality assessment of included studies was performed using the Quality Assessment tool for Diagnostic Accuracy Studies (QUADAS-2) checklist, and risk of bias and applicability were assessed according to patient selection, index test, reference standard, flow, and timing [19]. Funnel plots were also performed in order to assess publication bias.

\section{Data Synthesis}

Incremental yield (risk difference) of CMA was defined as the yield over karyotyping for each prenatal series. CNVs found at CMA analysis of $\geq 10 \mathrm{Mb}$ in size were considered detectable by conventional karyotyping, as previously considered by Shaffer et al. [10], and therefore excluded from the study. Incremental yield was calculated as the proportion of the abnormal results not detectable by karyotyping (pathogenic $\mathrm{CNV}<10 \mathrm{Mb}$ at CMA) di- 
Table 1. Summary of the 10 studies assessing the incremental yield of CMA over karyotyping in fetuses with FGR

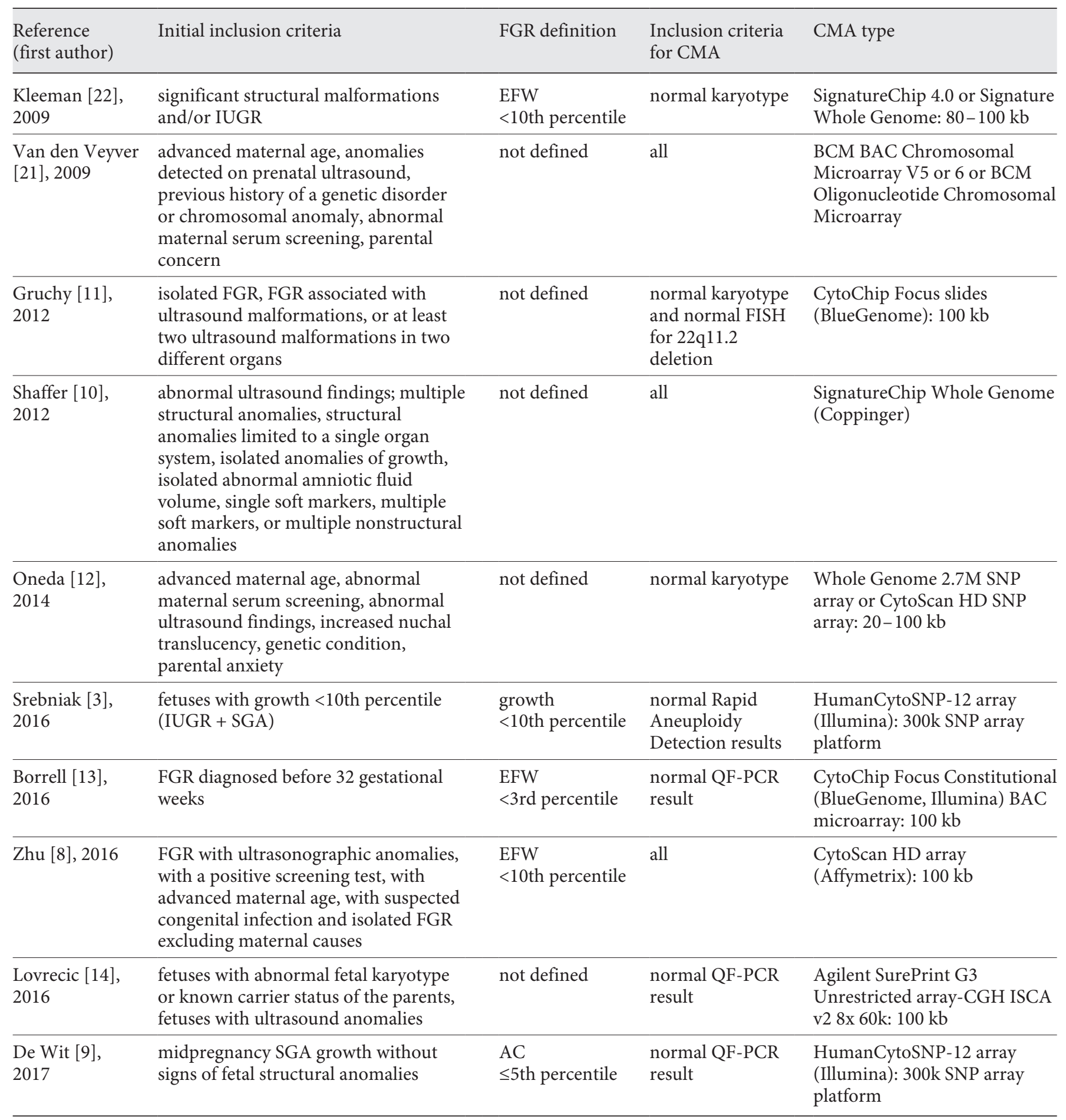

AC, abdominal circumference; CMA, chromosomal microarray analysis; EFW, estimated fetal weight; FGR, fetal growth restriction; FISH, fluorescence in situ hybridization; IUGR, intrauterine growth restriction; QF-PCR, quantitative fluorescence polymerase chain reaction; SGA, small for gestational age.

Chromosomal Microarray Analysis and Fetal Growth Restriction
Fetal Diagn Ther 2018;44:1-9

DOI: $10.1159 / 000479506$ 


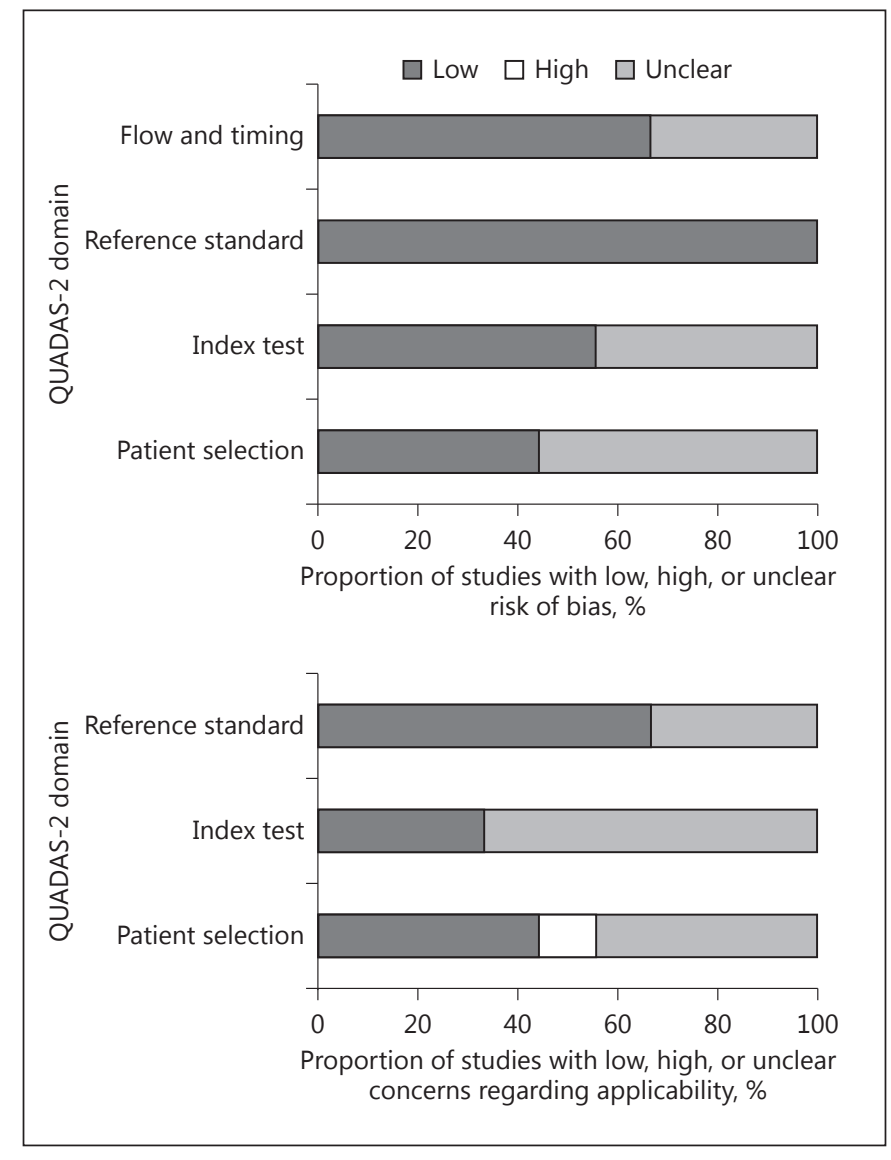

Fig. 2. Quality assessment summary of the included studies using the Quality Assessment tool for Diagnostic Accuracy Studies (QUADAS-2) checklist.

vided by the total number of cases with an eventual normal karyotype (after excluding $\mathrm{CNV} \geq 10 \mathrm{Mb}$ ). Variants of unknown significance were not included in this study. Series were stratified according to whether FGR was associated with fetal malformations or not. Nonmalformed fetuses included fetuses with FGR as an isolated finding and fetuses with FGR and a nonstructural anomaly, such as soft markers or abnormal amniotic fluid amount. A third group including FGR associated to nonstructural anomalies was attempted, but finally discarded since these findings were not supplied in many series. Risk differences were pooled (weighting by the inverse of variance) to estimate the overall and stratified CMA incremental yield using RevMan version 5.3.4, and the corresponding forest plots graphs were constructed [20]. Confidence intervals (CIs) were computed. Statistical heterogeneity was examined using the Higgins $I^{2}$ (quantitative) test. Taking into account the low statistical power of tests of heterogeneity, we considered statistically significant heterogeneity as Cochran Q test with $p<0.1$ or $I^{2}>30 \%$. A random-effects model was used when there was significant heterogeneity. We assessed publication bias graphically using funnel plot graphs. The $\chi^{2}$ test was used to assess differences in recurrent $\mathrm{CNV}$ occurrence between malformed and nonmalformed growth-restricted fetuses.

\section{Results}

The search resulted in 880 articles; 52 of these articles were reviewed fully, and 10 were selected to be included in the meta-analysis [3, 8-14, 21, 22]. Forty-two studies were excluded because they did not include an FGR group, because they included overlapping populations, or because the data required for the analysis could not be extracted. One series without an initial FGR subgroup was finally included because the authors provided us the missing data [12]. Two series from the same group were included as their most recent study included only nonmalformed FGR fetuses, while from the former only malformed FGR fetuses were included [3, 9]. Two CMA series including fetuses with ultrasound anomalies and only 3 FGR cases were also included [21,22]. The process of study revision and selection is outlined in Figure 1. Variants of unknown significance were not included in this study.

Table 1 displays the characteristics of the 10 studies, including the overall criteria for cases being included in the studies, criteria for undergoing CMA, and the type of microarray used in the study. FGR definition was provided in 5 studies, and the cutoffs used were the 10th percentile for the estimated fetal weight in 3 studies $[3,8$, 22 ], the 3 rd percentile for the estimated fetal weight in 1 study [13], and the 5th percentile for the abdominal circumference in 1 study [9]. Four studies included only fetuses with FGR, 4 studies included fetuses with different ultrasound anomalies, and the remaining 2 studies also included pregnancies with advanced maternal age and abnormal serum screening. In 3 studies CMA was performed after a normal result at karyotyping, in 4 after normal quantitative fluorescence polymerase chain reaction (QF-PCR) results, in 2 of them was it performed simultaneously to karyotyping, and in 1 as a stand-alone approach. Quality assessment of the included studies using QUADAS-2 is shown in Figure 2.

Forest plots with details of the 10 included studies and the pooled results from the meta-analysis are shown in Figures 3 and 4. Six studies included both nonmalformed and malformed FGR fetuses, 3 studies only nonmalformed FGR fetuses, and 1 only included malformed FGR fetuses. The pooled data from the reviewed studies show an overall $4 \%$ incremental yield of CMA over karyotyping (95\% CI 1-6\%) in nonmalformed FGR fetuses and an overall 10\% incremental yield (95\% CI 6-14\%) in malformed FGR fetuses. The observed incremental yield for each single study ranged from 0 to $17 \%$ in nonmalformed FGR fetuses and from 0 to $21 \%$ in mal- 


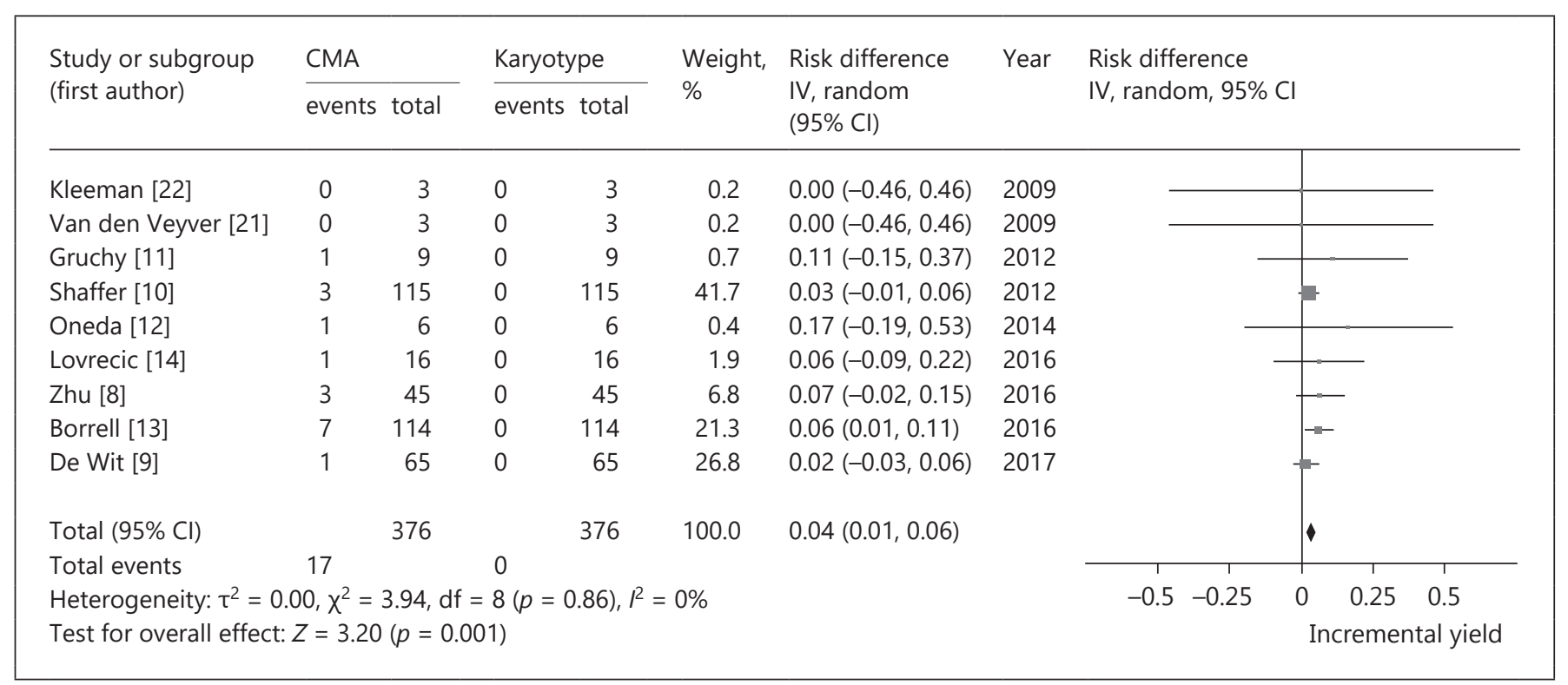

Fig. 3. Forest plot of incremental yield by chromosomal microarray analysis (CMA) over karyotyping in nonmalformed growth-restricted fetuses. Risk differences were pooled weighting by the inverse of variance (IV). Only the first author of each study is reported. CI, confidence interval.

\begin{tabular}{|c|c|c|c|c|c|c|c|c|c|c|}
\hline \multirow{3}{*}{$\begin{array}{l}\text { Study or subgroup } \\
\text { (first author) }\end{array}$} & \multicolumn{2}{|c|}{ CMA } & \multicolumn{2}{|c|}{ Karyotype } & \multirow{2}{*}{$\begin{array}{l}\text { Weight, } \\
\%\end{array}$} & \multirow{2}{*}{$\begin{array}{l}\text { Risk difference } \\
\text { IV, random } \\
(95 \% \mathrm{Cl})\end{array}$} & \multirow[t]{2}{*}{ Year } & \multirow{2}{*}{\multicolumn{3}{|c|}{$\begin{array}{l}\text { Risk difference } \\
\text { IV, random, } 95 \% \mathrm{Cl}\end{array}$}} \\
\hline & \multicolumn{2}{|c|}{ events total } & \multicolumn{2}{|c|}{ events total } & & & & & & \\
\hline & 1 & 6 & 0 & 6 & 1.4 & $0.17(-0.19,0.53)$ & 2012 & & & \\
\hline Shaffer [10] & 14 & 136 & 0 & 136 & 64.9 & $0.10(0.05,0.16)$ & 2012 & & t- & \\
\hline Oneda [12] & 0 & 2 & 0 & 2 & 0.5 & $0.00(-0.60,0.60)$ & 2014 & & & \\
\hline Zhu [8] & 1 & 25 & 0 & 25 & 16.5 & $0.04(-0.06,0.14)$ & 2016 & & - & \\
\hline Borrell [13] & 2 & 19 & 0 & 19 & 7.0 & $0.11(-0.06,0.27)$ & 2016 & & & \\
\hline Srebniak [3] & 5 & 24 & 0 & 24 & 6.1 & $0.21(0.04,0.38)$ & 2016 & & & \\
\hline Lovrecic [14] & 2 & 13 & 0 & 13 & 3.6 & $0.15(-0.07,0.38)$ & 2016 & & & \\
\hline Total $(95 \% \mathrm{Cl})$ & & 225 & & 225 & 100.0 & $0.10(0.06,0.14)$ & & & $\diamond$ & \\
\hline Total events & 25 & & 0 & & & & & 1 & $\mid$ & 1 \\
\hline \multirow{2}{*}{\multicolumn{8}{|c|}{$\begin{array}{l}\text { Heterogeneity: } \tau^{2}=0.00, \chi^{2}=3.29, \mathrm{df}=6(p=0.77), I^{2}=0 \% \\
\text { Test for overall effect: } Z=4.69(p<0.00001)\end{array}$}} & $-0.5-0.25$ & $0 \quad 0.25$ & 0.5 \\
\hline & & & & & & & & & Incremen & tal yield \\
\hline
\end{tabular}

Fig. 4. Forest plot of incremental yield by chromosomal microarray analysis (CMA) over karyotyping in malformed growth-restricted fetuses. Risk differences were pooled weighting by the inverse of variance (IV). Only the first author of each study is reported. CI, confidence interval.

formed FGR fetuses. There were 2 studies with more than 100 cases each. The larger series included 115 nonmalformed and 136 malformed fetuses and reported 3 and $10 \%$ incremental yield for each FGR group, respectively [10]. The Barcelona Multicenter Study was the sec- ond larger series, with 114 nonmalformed and 19 malformed FGR fetuses, reporting a $6 \%$ and a $10 \%$ incremental yield, respectively [13]. Two further cohorts, including 65 and 45 nonmalformed FGR fetuses, reported a $2-7 \%$ incremental yield $[8,9]$. The remaining studies 
Table 2. Pathogenic CNVs and size identified by CMA analysis in fetuses with FGR and normal karyotype

\begin{tabular}{|c|c|c|c|}
\hline FGR group & Ultrasound findings & Pathogenic CNVs & CNV size \\
\hline \multicolumn{4}{|l|}{ Nonmalformed } \\
\hline Gruchy [11], 2012 & None & arr Xp22.33(386804-1219147)x1 & $0.8 \mathrm{Mb}$ \\
\hline \multirow[t]{6}{*}{ Borrell [13], 2016} & None & arr $22 \mathrm{q} 11.21(17,662,989 \times 2,19,172,842-19,843,647 \times 3,22,691,548) \times 2$ & $670 \mathrm{~kb}$ \\
\hline & None & arr Xp22.31 $(6,223,645 \times 1,7,239,742-8,153,286 \times 0,8,227,525) \times 1$ & $913 \mathrm{~kb}$ \\
\hline & None & arr $15 q 26.3(97,368,574 \times 2,98,678,082-99,607,415 \times 1,100,187,983) \times 2$ & $930 \mathrm{~kb}$ \\
\hline & Oligohydramnios & 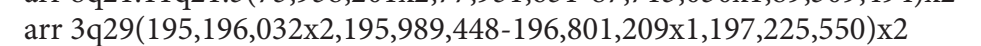 & $812 \mathrm{~kb}$ \\
\hline & Polyhydramnios & arr $22 \mathrm{q} 11.22 \mathrm{q} 11.23(22,691,548 \times 2,23,146,740-24,319,952 \times 3,5,254,126) \times 2$ & $1.17 \mathrm{Mb}$ \\
\hline & Polyhydramnios & arr $7 \mathrm{q} 11.23(72,583,171 \times 2,72,699,013-73,955,362 \times 1,74,227,093) \times 2$ & $1.25 \mathrm{Mb}$ \\
\hline Lovrecic [14], 2016 & None & arr $2 q 13(111,442,130-113,065,779) \times 1$ & $1.6 \mathrm{Mb}$ \\
\hline \multirow{2}{*}{ Zhu [8], 2016} & Oligohydramnios & arr $17 \mathrm{p} 12(14,108,911-15,473,312) \times 3$ & $1.3 \mathrm{Mb}$ \\
\hline & None & arr $7 \mathrm{q} 11.23(72,701,018-74,143,030) \mathrm{x} 1$ & $1.4 \mathrm{Mb}$ \\
\hline \multirow[t]{7}{*}{ Srebniak [3], 2016} & Cleft lip & $\operatorname{arr}[$ hg18] 4p16.3p16.1(38,283x2,38,283-8,321,040x1,8,321,040)x2dn & $8.3 \mathrm{Mb}$ \\
\hline & Complex congenital & $\operatorname{arr}[$ hg18] $5 \mathrm{q} 35.3(179,278,602 \times 2,179286,688-180,638,145 \times 1,180,857$, & $1.5 \mathrm{Mb} /$ \\
\hline & heart disease & $\begin{array}{l}866 \times 2) \text { mat, } 16 \mathrm{q} 24.2 \mathrm{q} 24.3(86,358,459 \times 2,86,364 \\
482-88,685,456 \times 3,88,827,254) \times 2 \mathrm{mat}\end{array}$ & $2.5 \mathrm{Mb}$ \\
\hline & $\begin{array}{l}\text { Corpus callosum agenesis, } \\
\text { congenital heart disease, } \\
\text { aberrant position lower leg, } \\
\text { single umbilical artery }\end{array}$ & 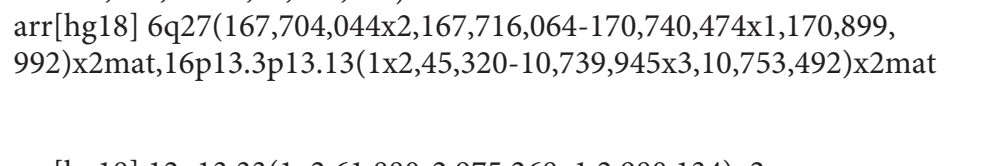 & $\begin{array}{l}3.2 \mathrm{Mb} / \\
(10.7 \mathrm{Mb})\end{array}$ \\
\hline & Thumb malformation, & $\operatorname{arr}[$ hg18] 12p13.33(1x2,61,880-2,975,268x1,2,980,134)x2 & $2.9 \mathrm{Mb} /$ \\
\hline & suspected cardiomyopathy & $\mathrm{x} 2 \mathrm{dn}, 19 \mathrm{p} 13.3 \mathrm{p} 13.2(1 \times 2,218,039-7,499,589 \times 3,7,499,589 \times 2) \mathrm{dn}$ & $7.3 \mathrm{Mb}$ \\
\hline & $\begin{array}{l}\text { Microcephaly, plexus } \\
\text { choroideus cysts, nuchal } \\
\text { fold, echogenic focus heart, } \\
\text { club foot }\end{array}$ & $\begin{array}{l}\operatorname{arr}[\mathrm{hg} 18] 22 \mathrm{q} 11.21(19,3354,880 \times 2,19,380,522-19,792,353 \times 1,20,125 \text {, } \\
656 \times 2) \text { mat }\end{array}$ & $590 \mathrm{~kb}$ \\
\hline Lovrecic [14], 2016 & Multicystic kidney & arr $16 \mathrm{p} 12.2(21,837,492-22,407,931) \times 1$ & $570 \mathrm{~kb}$ \\
\hline
\end{tabular}

The ISCN nomenclature was preferred and used when provided by the authors. CMA, chromosomal microarray analysis; CNV, copy number variant; FGR, fetal growth restriction; UPD, uniparental disomy.

had a small FGR subgroup including 3-19 cases and reported detection rates ranging from 0 to $17 \%$ in nonmalformed FGR fetuses $[11,12,14,21,22]$ and from 0 to $21 \%$ in malformed FGR fetuses [3, 11, 12]. Funnel plots to assess publication bias are provided in online supplementary Figures $1 \mathrm{~S}$ and $2 \mathrm{~S}$.

Clinically significant submicroscopic CNVs found in fetuses with growth restriction are outlined in Table 2. Twenty-five of the 42 pathogenic CNVs were specified by the authors, and their size ranged between $590 \mathrm{~kb}$ and 8.3 $\mathrm{Mb}$. The most frequently found CNVs were $22 \mathrm{q} 11.2 \mathrm{du}-$ plication $(n=5)$, Xp22.3 deletion $(n=3)$, and $7 \mathrm{q} 11.23$ deletion (Williams-Beuren syndrome) $(n=3)$. These three recurrent CNVs account for 18\% (2/11) of those found in malformed fetuses, increasing significantly to $64 \%(9 / 14)(p=0.02)$ in those nonmalformed, resulting in $0.9 \%(2 / 225)$ and $2.4 \%(9 / 376)$ prevalences $(p=0.18)$, respectively in both groups of FGR. 


\section{Discussion}

This systematic review and meta-analysis supports the use of CMA in karyotypically normal fetuses with FGR, with a $4 \%(95 \%$ CI 1-6\%) incremental yield over conventional karyotype in nonmalformed FGR fetuses, increasing to $10 \%$ (95\% CI 6-14\%) in malformed FGR fetuses.

Scarce reports have assessed the potential value of CMA in fetuses with FGR and normal karyotype, since our systematic review only found 10 series that fulfilled the search criteria, including a range from 3 to 136 fetuses with FGR. Although it is well established that prenatal CMA leads to the detection of clinically relevant microdeletions and microduplications in fetuses with ultrasound anomalies and normal karyotype, FGR is rarely specified as a reason for testing when found in isolation. In addition, none of the prenatal CMA guidelines specify FGR as a reason for performing it. The American guidelines [18] recommend CMA in "a fetus with one or more major structural anomalies identified on ultrasonographic examination," and very similar indications were stated in the British [17] and Canadian guidelines [15]. Although strictly speaking FGR can be considered a fetal structural anomaly, common use tends to consider that "structural anomalies" and "malformations" have the same meaning.

The most frequently encountered pathogenic imbalances were five 22q11.2 microduplication syndromes [3, 8, 9, 13], three Xp22.3 [11-13] deletion syndromes, and three Williams-Beuren syndromes (7q11.23 microdeletion) $[8,11,13]$. Three of the 22q11.2 duplicated regions were reciprocal to the DiGeorge/velocardiofacial syndrome recurrent deletions, one was a more distal 22q11.22q11.23 microduplication [13], and in the last no details were given by the authors [9]. Reciprocal microdeletion and microduplication syndromes are expected to share some clinical features, and both $22 \mathrm{q} 11.2$ microdeletion and microduplication syndromes may present with FGR and learning difficulties [23, 24]. The deletion of the Xp22.3 region encompasses the VCX3A and STS genes. Most of the patients with STS deletion have Xlinked ichthyosis as the only clinical feature, while it is believed that patients with more complex disorders including intellectual disability could result from a contiguous gene deletion. In fact, the $V C X 3 A$ gene was previously proposed as the candidate gene for X-linked nonspecific intellectual disability in patients with X-linked ichthyosis [25]. Finally, Williams-Beuren syndrome is a multisystemic neurodevelopmental disorder characterized by a distinct facial appearance, cardiac anomalies, cognitive and developmental anomalies, and connective tissue anomalies. Although prenatal diagnosis of this syndrome cannot be easily performed because only few of the phenotype features can be detected by ultrasound, FGR was present in most of the prenatal reports of this syndrome [26]. Interestingly enough, these three recurrent CNVs account for more than half of those found in nonmalformed fetuses with growth restriction, achieving a $2.4 \%$ prevalence in those fetuses.

Regarding the implications of this increased ability to diagnose future pregnancies, a key issue is establishing the inheritance pattern for any of the submicroscopic anomalies found. Generally speaking, when the clinical implications are severe, as in Williams-Beuren syndrome, a "de novo" appearance can be assumed, but in milder conditions, such as del22q11, some cases will be inherited, and therefore a $50 \%$ recurrence is expected, but the phenotype may vary and cannot be predicted. The parents should be studied with CMA in all cases to search for an inherited parental $\mathrm{CNV}$, particularly mothers with a $\mathrm{CNV}$ located on the $\mathrm{X}$ chromosome, and by karyotyping to search for parental chromosome rearrangements.

The main strength of our study is that this is the first systematic review and meta-analysis on the incremental yield of CMA over karyotyping in fetuses with FGR. A major limitation of this meta-analysis is the high heterogeneity found among series, mainly due to the different diagnostic criteria to define FGR, or simply lack of definition. This limitation is not specific to our meta-analysis because there is a lack of consensus in the definition and clinical management of this condition worldwide. Recently, the results of a Delphi consensus procedure have been reported with the aim of achieving a common definition for FGR [27]. Heterogeneity was also found in the clinical design (CMA performed simultaneously to karyotyping, after a normal karyotype, or after normal fluorescence in situ hybridization or QF-PCR results), the use of different CMA platforms, and the sample size of the series. With this high heterogeneity, pooled rates must be considered with caution. Another limitation of the study is that after CMA some genetic anomalies remain undetected: (a) anomalies confined to the placenta causing FGR undetectable in amniotic fluid, (b) uniparental isodisomy (if CGH-arrays are used) or methylation changes, two mechanisms that can cause Silver-Russell syndrome, and (c) monogenic diseases, the vast majority of which cannot be detected by CMA. A final limitation of our study is related to the fact that the rates obtained in this meta-analysis may underestimate the real prevalence of submicroscopic changes in FGR, because FGR is 
one of the most common causes of stillbirth, and CMA has not yet been introduced as elective genetic testing in those events.

In conclusion, this systematic review and meta-analysis revealed that CMA analysis provides a $4 \%$ incremental yield in nonmalformed FGR fetuses with normal karyotype and a $10 \%$ incremental yield in malformed FGR fetuses. This finding could allow fetal medicine specialists to improve antenatal counseling in cases of isolated FGR by improving diagnostic accuracy and establishing protocols for index and future pregnancy outcome. Further research on the genetic causes of FGR is needed, and whole-exome sequencing appears to be the next step, after chromosomal and submicroscopic anomalies have been ruled out, to reveal single-gene disorders, the third greatest group of genetic anomalies.

\section{Disclosure Statement}

The authors have no conflicts of interest to declare. This study received no funding support.

\section{References}

1 Snijders RJ, Sherrod C, Gosden CM, Nicolaides KH: Fetal growth retardation: associated malformations and chromosomal abnormalities. Am J Obstet Gynecol 1993;168:547555.

2 Lyons JK, Crandall JM, del Campo M: Smith's Recognizable Patterns of Human Malformation, ed 7. Philadelphia, PA, Elsevier Saunders, 2013.

3 Srebniak MI, Diderich KE, Joosten M, Govaerts LC, Knijnenburg J, de Vries FA, Boter M, Lont D, Knapen MF, de Wit MC, Go AT, Galjaard RH, Van Opstal D: Prenatal SNP array testing in 1000 fetuses with ultrasound anomalies: causative, unexpected and susceptibility CNVs. Eur J Hum Genet 2016;24:645651.

4 Kan AS, Lau ET, Tang WF, Chan SS, Ding SC, Chan KY, Lee CP, Hui PW, Chung BH, Leung $\mathrm{KY}$, Ma T, Leung WC, Tang MH: Whole-genome array CGH evaluation for replacing prenatal karyotyping in Hong Kong. PLoS One 2014;9:e87988.

5 Hillman SC, McMullan DJ, Hall G, Togneri FS, James N, Maher EJ, Meller CH, Williams D, Wapner RJ, Maher ER, Kilby MD: Use of prenatal chromosomal microarray: prospective cohort study and systematic review and meta-analysis. Ultrasound Obstet Gynecol 2013;41:610-620.

6 Lee CN, Lin SY, Lin CH, Shih JC, Lin TH, Su YN: Clinical utility of array comparative genomic hybridisation for prenatal diagnosis: a cohort study of 3171 pregnancies. BJOG 2012; 119:614-625.

7 Tyreman M, Abbott KM, Willatt LR, Nash R, Lees C, Whittaker J, Simonic I: High resolution array analysis: diagnosing pregnancies with abnormal ultrasound findings. J Med Genet 2009;46:531-541.

8 Zhu H, Lin S, Huang L, He Z, Huang X, Zhou Y, Fang Q, Luo Y: Application of chromosomal microarray analysis in prenatal diagnosis of fetal growth restriction. Prenat Diagn 2016;36:686-692.
9 De Wit MC, Srebniak MI, Joosten M, Govaerts LC, Kornelisse RF, Papatsonis DN, De Graaff K, Knapen MF, Bruggenwirth HT, De Vries FA, Van Veen S, Van Opstal D, Galjaard RJ, Go AT: Prenatal and postnatal findings in small-for-gestational-age fetuses without structural ultrasound anomalies at 18-24 weeks. Ultrasound Obstet Gynecol 2017;49: 342-348.

10 Shaffer LG, Rosenfeld JA, Dabell MP, Coppinger J, Bandholz AM, Ellison JW, Ravnan JB, Torchia BS, Ballif BC, Fisher AJ: Detection rates of clinically significant genomic alterations by microarray analysis for specific anomalies detected by ultrasound. Prenat Diagn 2012;32:986-995.

11 Gruchy N, Decamp M, Richard N, JeannePasquier C, Benoist G, Mittre H, Leporrier N: Array CGH analysis in high-risk pregnancies: comparing DNA from cultured cells and cellfree fetal DNA. Prenat Diagn 2012;32:383388.

12 Oneda B, Baldinger R, Reissmann R, Reshetnikova I, Krejci P, Masood R, OchsenbeinKölble N, Bartholdi D, Steindl K, Morotti D, Faranda M, Baumer A, Asadollahi R, Joset P, Niedrist D, Breymann C, Hebisch G, Hüsler M, Mueller R, Prentl E, Wisser J, Zimmermann R, Rauch A: High-resolution chromosomal microarrays in prenatal diagnosis significantly increase diagnostic power. Prenat Diagn 2014;34:525-533.

13 Borrell A, Grande M, Meler E, Sabrià J, Mazarico E, Muñoz A, Rodriguez-Revenga L, Badenas C, Figueras F: Genomic microarray in fetuses with early growth restriction: a multicenter study. Fetal Diagn Ther 2016, Epub ahead of print.

14 Lovrecic L, Remec ZI, Volk M, Rudolf G, Writzl K, Peterlin B: Clinical utility of array comparative genomic hybridisation in prenatal setting. BMC Med Genet 2016;17:81.
15 Duncan A, Langlois S; SOGC Genetics Committee; CCMG Prenatal Diagnosis Committee: Use of array genomic hybridization technology in prenatal diagnosis in Canada. J Obstet Gynaecol Can 2011;33:1256-1259.

16 South ST, Lee C, Lamb AN, Higgins AW, Kearney HM; Working Group for the American College of Medical Genetics and Genomics Laboratory Quality Assurance Committee: ACMG Standards and Guidelines for constitutional cytogenomic microarray analysis, including postnatal and prenatal applications: revision 2013. Genet Med 2013;15: 901-909.

17 Gardiner C, Wellesley D, Kilby MD, Kerr B; on behalf of the Joint Committee on Genomics in Medicine: The Royal College of $\mathrm{Pa}$ thologists. Recommendations for the use of chromosome microarray in pregnancy 2015. https://www.rcpath.org/.

18 Committee on Genetics and the Society for Maternal-Fetal Medicine: Committee Opinion No.682: Microarrays and Next-Generation Sequencing Technology: The Use of Advanced Genetic Diagnostic Tools in Obstetrics and Gynecology. Obstet Gynecol 2016; 128:e262-e268.

19 Whiting PF, Rutjes AW, Westwood ME, Mallett S, Deeks JJ, Reitsma JB, Leeflang MM, Sterne JA, Bossuyt PM; QUADAS-2 Group: QUADAS-2: a revised tool for the quality assessment of diagnostic accuracy studies. Ann Intern Med 2011;155:529-536.

20 Review Manager 5.3.4. The Cochrane Collaboration. Cochrane Informatics and Knowledge Management Department.

21 Van den Veyver IB, Patel A, Shaw CA, Pursley AN, Kang SH, Simovich MJ, Ward PA, Darilek S, Johnson A, Neill SE, Bi W, White LD, Eng CM, Lupski JR, Cheung SW, Beaudet AL: Clinical use of array comparative genomic hybridization $(\mathrm{aCGH})$ for prenatal diagnosis in 300 cases. Prenat Diagn 2009;29: 29-39. 
22 Kleeman L, Bianchi DW, Shaffer LG, Rorem E, Cowan J, Craigo SD, Tighiouart H, WilkinsHaug LE: Use of array comparative genomic hybridization for prenatal diagnosis of fetuses with sonographic anomalies and normal metaphase karyotype. Prenat Diagn 2009;29: 1213-1217.

23 Ensenauer RE, Adeyinka A, Flynn HC, Michels VV, Lindor NM, Dawson DB, Thorland EC, Lorentz CP, Goldstein JL, McDonald MT, Smith WE, Simon-Fayard E, Alexander AA, Kulharya AS, Ketterling RP, Clark RD, Jalal SM: Microduplication 22q11.2, an emerging syndrome: clinical, cytogenetic, and molecu- lar analysis of thirteen patients. Am J Hum Genet 2003;73:1027-1040.

24 Wentzel C, Fernström M, Ohrner Y, Annerén G, Thuresson AC: Clinical variability of the 22q11.2 duplication syndrome. Eur J Med Genet 2008;51:501-510.

25 Ben Khelifa H, Soyah N, Ben-AbdallahBouhjar I, Gritly R, Sanlaville D, Elghezal H, Saad A, Mougou-Zerelli S: Xp22.3 interstitial deletion: a recognizable chromosomal abnormality encompassing VCX3A and STS genes in a patient with X-linked ichthyosis and mental retardation. Gene 2013;527: 578-583.
26 Marcato L, Turolla L, Pompilii E, Dupont C, Gruchy N, De Toffol S, Bracalente G, Bacrot S, Troilo E, Tabet AC, Rossi S, Delezoïde AL, Baldo D, Leporrier N, Maggi F, Molin A, Pilu G, Simoni G, Vialard F, Grati FR: Prenatal phenotype of Williams-Beuren syndrome and of the reciprocal duplication syndrome. Clin Case Rep 2014;2:25-32.

27 Gordijn SJ, Beune IM, Thilaganathan B, Papageorghiou A, Baschat AA, Baker PN, Silver RM, Wynia K, Ganzevoort W: Consensus definition of fetal growth restriction: a Delphi procedure. Ultrasound Obstet Gynecol 2016; 48:333-339. 